Available Online at ESci Journals

Journal of Plant Breeding and Genetics

ISSN: 2305-297X (Online), 2308-121X (Print)

http://www.escijournals.net/JPBG

\title{
GGE BIPLOT ANALYSIS OF GENOTYPE BY ENVIRONMENT INTERACTION AND GRAIN YIELD STABILITY OF BREAD WHEAT GENOTYPES IN CENTRAL ETHIOPIA
}

\author{
aGadisa A. Wardofa*, aDawit Asnake, bHussein Mohammed \\ a Kulumsa Agricultural Research Center, Assela, Ethiopia. \\ b Hawassa University College of Agriculture, Hawassa, Ethiopia.
}

\section{A B S T R A C T}

GGE biplot is an effective method based on principal component analysis to fully explore mega-environments trials data. The study conducted was to identify the best performing, high yielding stable advanced bread wheat genotype for selection environments, the identification of mega-environments and analysis of the ideal genotype and environment by GGE biplot method. Fifteen bread wheat genotypes were evaluated using RCBD with four replications at six locations in Ethiopia. The results of combined analysis of variance for grain yield of fifteen bread wheat genotypes indicated that genotype, environment and GEI were highly significant $(\mathrm{P}<0.001)$. The factors explained showed bread wheat genotypes grain yield was affected by environment (35.28\%), genotype (33.46\%) and GEI (31.45\%). The first two PC axes of GGE explained $88.7 \%$ of G+GEI and divided the six locations into three major groups: Group1 included Asasa, Kulumsa and Arsi Robe (moderately discriminating locations); Group2 had the highland wheat producing locations Holeta and Bekoji (most discriminating locations), while Group3 contain Dhera (least discriminating location), a moisture stress location in the rift valley. Locations within the same group were closely correlated and provided redundant information about the genotypes. Testing can be performed in any one of the locations within a group. Genotype ETBW8078 and ETBW8459 were more stable as well as low yielding. Considering simultaneously yield and stability, genotype ETBW9045 and Hiddase showed the best performances suggesting their adaptation to a wide range of environments. Lemu, ETBW8084 and ETBW8065 were considered as desirable. Genotype ETBW8075 was the least stable with low yield and had a large contribution to the GEI, having the longest distance from the average environment. ETBW9470 was specifically adapted to Group1 locations while ETBW8070 was adapted to Group2 environments. Based on yield performance advanced lines ETBW9470 and ETBW8070 are recommended to be included in variety verification trials for further release.

Keywords: Adapted, Discriminating, Grain yield, Stable.

\section{INTRODUCTION}

Wheat is one of the most important cereal crops cultivated in Ethiopia. It is an important and most widely cultivated food crop in the world and quantity produced is more than that of any other crop, feeding about $40 \%$ of the world population. This crop played a central role in combating hunger and improving global food security. The grains of this plant provide about $20 \%$ of all calories and proteins consumed by people on the globe (Shiferaw et al., 2013). Wheat production in Ethiopia ranks fourth in area coverage surpassed only by teff, maize and sorghum and it is the third largest crop in total

* Corresponding Author:

Email: gadalemu@gmail.com

(c) 2019 ESci Journals Publishing. All rights reserved. production (Central Statistical Agency, 2014).

Plant breeders perform multi-environment trials to evaluate new improved genotypes across test environments before a specific genotype is released for production to supply growers. In such experiments, GEI is commonly evaluated (Yan et al., 2007; Karimizadeh et al., 2012). GEI refers to a different ranking of genotypes across environments and may complement the selection process and recommendation of a genotype for a target environment (Gauch, 2006). It may also reduce the selection efficiency in different breeding programs because, in a GEI, measured traits are less predictable and cannot be interpreted using main effects (genotype or environment) and need more analysis (Gauch et al., 2008). GEI is also one of the most important reasons for 
the failure or decreased efficiency of breeding efforts to serve small resource-poor farmers in different areas (Kaya et al., 2006; Mitrović et al., 2012).

Plant breeders perform multi-environment trials to select favourable genotypes based on both mean yield and performance stability and to determine whether a test environment is homogeneous should be divided into various mega-environments (Gauch, 2006; Yan and Kang, 2003). A different statistical model was used to describe GEI and facilitate genotype recommendations in MET such as stability variance (Shukla, 1972), coefficient of variability (Francis and Kannenberg, 1978) and AMMI (Gauch, 2006) have been commonly used to analyze MET data to reveal patterns of GEI. Yan et al. (2000) proposed another methodology known as GGE biplot for the graphical display of GEI pattern of MET data with many advantages. GGE biplot analysis considers both genotype and GEI effects and graphically displays GEI in a two-way table (Yan et al., 2001). GGE biplot is an effective method based on principal component analysis to fully explore MET data. It allows visual examination of the relationships among the test environments, genotypes and the GEI. The main objectives of the present study are to identify the best performing high yielding stable advanced bread wheat genotype for selection environments, the identification of mega-environments and analysis of the ideal genotype and environment by GGE biplot method.

\section{MATERIAL AND METHODS}

Experimental Materials and Design: Thirteen advanced bread wheat genotype and two recently released varieties were evaluated across six locations in 2017 / 2018 main cropping seasons. Description of test locations and wheat genotype is provided in Table 1 and Table 2 , respectively.

Table 1. Location and descriptions of the weather condition for six locations.

\begin{tabular}{|c|c|c|c|c|c|c|c|c|}
\hline \multirow{2}{*}{ Location } & \multicolumn{2}{|c|}{ Geographic position } & \multirow{2}{*}{ Altitude } & \multirow{2}{*}{$\begin{array}{l}\text { Soil } \\
\mathrm{pH}\end{array}$} & \multirow{2}{*}{ Soil type } & \multicolumn{2}{|c|}{ Temperature $\left({ }^{\circ} \mathrm{C}\right)$} & \multirow{2}{*}{$\begin{array}{l}\text { Rainfall } \\
(\mathrm{mm})\end{array}$} \\
\hline & Latitude & Longitude & & & & Min & $\operatorname{Max}$ & \\
\hline Kulumsa & $08^{\circ} 01^{\prime} 10^{\prime \prime N}$ & 39॰09'11"E & 2200 & 6 & Luvisol & 10.5 & 22.8 & 820 \\
\hline Asasa & $07^{\circ} 07^{\prime} 09^{\prime \prime} \mathrm{N}$ & 39011'50"E & 2000 & 6.5 & Gleysol & 5.8 & 24 & 620 \\
\hline Dhera & $08^{\circ} 19^{\prime} 10^{\prime \prime} \mathrm{N}$ & 39019'13"E & 1650 & 7 & Andosol & 14 & 27.8 & 680 \\
\hline Bekoji & $07^{\circ} 32^{\prime} 37^{\prime \prime N}$ & $39^{\circ} 15^{\prime} 21^{\prime \prime} \mathrm{E}$ & 2780 & 5 & Nitosol & 7.9 & 18.6 & 1020 \\
\hline Arsi Robe & $07^{\circ} 53^{\prime} 02^{\prime \prime N}$ & $39^{\circ} 37^{\prime} 40^{\prime \prime} \mathrm{E}$ & 2420 & 5.6 & Vertisol & 6 & 21.1 & 890 \\
\hline Holeta & NA & NA & 2400 & 5 & Nitosol & 6.2 & 22.1 & 1044 \\
\hline
\end{tabular}

The field experiment was laid out in RCBD with four replications. The experimental field plot was 6 rows of $2.5 \mathrm{~m}$ long with a $0.2 \mathrm{~m}$ inter-row spacing. Each plot was planted at a rate of $150 \mathrm{~kg}$ ha- 1 . The fertilizer application and other crop management practices were done as per the recommendations of each test locations. Weeds grown in the plots were removed manually starting from two weeks after sowing.

Table 2. The names, pedigree and selection history of the genotypes were evaluated in the experiment in 2016/17 cropping season at six locations.

\begin{tabular}{lll}
\hline \multicolumn{1}{c}{ Name } & \multicolumn{1}{c}{ Pedigree } & \multicolumn{1}{c}{ Selection History } \\
\hline Lemu & WAXWING*2/HEILO & \\
\hline ETBW8070 & Line 1 Singh/ETBW4919 & KU07-01-0KU-0KU-0KU-0BK2-22KU \\
\hline ETBW8078 & Line 1 Singh/(Cham6/WW1402) & KU07-04-0KU-0KU-0KU-0BK1-4KU \\
\hline ETBW8084 & Line 3 Singh/(Cham6/WW1402) & KU07-07-0KU-0KU-0KU-0BK1-3KU \\
\hline ETBW8311 & ND643/2*WBLL1/3/KIRITATI//PRL/2*PASTOR/ & CMSS07B00823T-099TOPY-099M-099Y- \\
& 4/KIRITATI//PBW65/2*SERI.1B & 099M-7WGY-0B \\
\hline ETBW8065 & Line 1 Singh/ETBW4919 & KU07-01-0KU-0KU-0KU-0BK1-5KU \\
\hline ETBW8427 & SERI.1B//KAUZ/HEVO/3/AMAD/4/PYN/BAU//M & ICW06-50208-5AP-0AP-0AP -02 SD \\
& ILAN/5/ICARDA-SRRL-1 & \\
\hline ETBW8459 & CHIL-1//VEE'S'/SAKER'S' & ICW99-0026-7AP-0AP-0AP-9AP-0AP- \\
\hline
\end{tabular}




\begin{tabular}{lll}
\hline & & $\begin{array}{l}\text { 0DZ/0AP-0DZ/0KUL/0SIN/0AP-0NJ/0AP- } \\
\text { 0ALK/0AP }\end{array}$ \\
\hline ETBW9037 & SWSR22T.B./2*BLOUK \#1//WBLL1*2/KURUKU & $\begin{array}{l}\text { CMSS08Y01116T-099M-099Y-099M-099NJ- } \\
\text { 099NJ-23WGY-0B }\end{array}$ \\
\hline ETBW9045 & KINDE/4/CMH75A.66//H567.71/5*PVN/3/SERI & CMSS09Y00603S-099Y-17M-0WGY-6B-0Y \\
\hline ETBW8075 & Line 1 Singh/(Cham6/WW1402) & KU07-04-0KU-0KU-0KU-0BK1-1KU \\
\hline ETBW9464 & MARCHOUCH*4/SAADA/3/2*FRET2/KUKUNA//F & CMSS10B00928T-099TOPY-099M-099NJ- \\
& RET2*2/4/TRCH/SRTU//KACHU & 099NJ-13WGY-0B \\
\hline ETBW9466 & ATTILA/3*BCN//BAV92/3/TILHI/5/BAV92/3/PR & CMSS10B01047T-099TOPY-099M-099NJ- \\
& L/SARA//TSI/VEE\#5/4/CROC_1/AE.SQUARROSA & 099NJ-2WGY-0B \\
& (224)//2*OPATA*2/6/HUW234+LR34/PRINIA// & \\
& UP2338*2/VIVITSI & \\
\hline ETBW9470 & BAVIS\#1/5/W15.92/4/PASTOR//HXL7573/2*BA & CMSA10M00485S-099ZTM-099NJ-099NJ- \\
& 6/3/WBLL1 & \\
\hline Hidasse & YANAC/3/PRL/SARA//TSI/VEE\#5/4/CR0C- & \\
& 1/AE.SQUAROSA (224)//OPATTA & \\
\hline
\end{tabular}

Data collection: Data was collected on the following traits: days to heading, days to maturity, grain filling period, number of grains per spike, number of spikelets per spike, plant height, number of tillers per plant, spike length, biomass yield, harvest index, TKW, HLW and grain yield per plot.

Statistical Analysis: The grain yield data for fifteen bread wheat in six environments were used to the combined analysis of variance (ANOVA) to determine the effects of the environment, genotype and GEI. Before combining the data, Bartlett's test was used to determine the homogeneity of variances between environments to determine the validity of the combined ANOVA on the data and the data collected was homogenous. The GGE biplot is a biplot that displays the GGE part of MET data The GGE biplot was built according to the formula given by Yan et al. (2000):

$$
Y_{i j}-\mu-\beta_{j}=\lambda_{1} \xi_{i 1} \eta_{j 1}+\lambda_{2} \xi_{i 2} \eta_{j 2}+\epsilon_{i j}
$$

where $Y_{i j}$ is the mean for the $i^{\text {th }}$ genotype in the $j^{\text {th }}$ environment, $\mu$ is the grand mean $\beta_{j}$ is the main effect of environment $j, \lambda_{1}$ and $\lambda_{2}$ are the singular values of the $1^{\text {st }}$ and $2^{\text {nd }}$ principal components, $\xi_{i 1}$ and $\xi_{i 2}$ are the PC1 and PC2 scores, respectively, for genotype $i^{t h}, \eta_{j 1}$ and $\eta_{j 2}$ are the eigenvectors for the $j^{\text {th }}$ environment for PC1 and PC2 and $\epsilon_{i j}$ is the residual error term.

\section{RESULT AND DISCUSSION}

According to the results of combined analysis of variance (Table 3) for grain yield genotype, environment and GEI were highly significant $(\mathrm{P}<0.001)$ for grain yield. Mohamed and Ahmed (2013) and Melkamu et al. (2015) reported that bread wheat grain yield was significantly affected by the environment. The highly significant GEI effects suggest that genotypes may be selected for adaptation to specific environments, which is in line with the findings of Akter et al. (2015) in GGE biplot analysis for yield stability in multi-environment trials of promising hybrid rice. The factors explained showed that bread wheat genotype grain yield was affected by environment (35.28\%), genotype (33.46\%) and GEI (31.45\%).

Table 3. Combined analysis of variance of grain yield for 15 bread genotypes evaluated at six environments.

\begin{tabular}{lcccc}
\hline Source of Variation & D.f & Sum Square & Mean square & Explained\% \\
\hline Genotype & 14 & 206.3 & $14.74^{* * *}$ & 33.46 \\
Rep(Env't) & 18 & 19.03 & 0.7 & - \\
Environment & 5 & 217.53 & $43.51^{* * *}$ & 35.28 \\
Interactions & 70 & 192.67 & $2.75^{* * *}$ & 31.45 \\
Error & 252 & 98.46 & 0.432 & - \\
Total & 359 & 733.99 & - & - \\
\hline
\end{tabular}


The genotype ETBW9470 ranked first in three of the six environments (Arsi Robe, Asasa and Kulumsa). Similarly, two other best-performing genotypes included ETBW8070 (Bekoji and Holeta) and ETBW9466 (Dhera) each ranking first in three of the environments. Genotype ETBW9470 showed the best yield of $6.56 \mathrm{t} / \mathrm{ha}$ in the highest-yielding environment Kulumsa, whereas ETBW9466 showed the best yield of $3.87 \mathrm{t} / \mathrm{ha}$ in the lowest-yielding environment Dhera (Table 4). In general, the ranking of genotypes changes from one environment to another and this is also an indication for the existence of $\mathrm{G} \times \mathrm{E}$ interaction due to variation among the testing locations and this result is in agreement with the findings of Tarakanovas and Ruzgas (2006) and Temesgen et al. (2015) who reported that the GEI was highly significant reflecting the differential response of genotypes in various environments.

Table 4. Mean values of bread wheat genotype grain yield (t/ha) each environment

\begin{tabular}{|c|c|c|c|c|c|c|c|}
\hline Genotype & Kulumsa & Asasa & Dhera & Bekoji & A. Robe & Holeta & Mean \\
\hline Lemu & $4.57^{d}$ & $3.76^{\mathrm{de}}$ & $3.00^{\mathrm{b}-\mathrm{e}}$ & $3.25^{\mathrm{bc}}$ & $3.65^{b c}$ & $5.34^{\mathrm{ab}}$ & $3.93^{\mathrm{b}-\mathrm{d}}$ \\
\hline ETBW8070 & $4.55^{\mathrm{d}}$ & $5.10^{\mathrm{b}}$ & $3.44^{\mathrm{a}-\mathrm{d}}$ & $4.81^{\mathrm{a}}$ & $3.86^{\mathrm{bc}}$ & $5.86^{\mathrm{a}}$ & $4.60^{\mathrm{ab}}$ \\
\hline ETBW8078 & $4.95^{\mathrm{cd}}$ & $3.61^{\mathrm{e}}$ & $3.15^{\mathrm{a}-\mathrm{e}}$ & $2.04 \mathrm{de}$ & $3.27 \mathrm{bc}$ & $3.31^{c}$ & $3.39 \mathrm{~cd}$ \\
\hline ETBW8084 & $6.36^{\mathrm{a}}$ & $4.89^{b}$ & $2.90^{c-e}$ & $2.66^{\mathrm{cd}}$ & $4.08^{\mathrm{b}}$ & $3.43^{c}$ & $4.05^{\mathrm{a}-\mathrm{d}}$ \\
\hline ETBW8311 & $4.50^{\mathrm{d}}$ & $3.88^{\mathrm{de}}$ & $3.05^{\mathrm{a}-\mathrm{e}}$ & $1.25^{\mathrm{ef}}$ & $3.31^{b c}$ & $2.69^{\mathrm{cd}}$ & $3.11^{\mathrm{d}}$ \\
\hline ETBW8065 & $4.56^{d}$ & $4.87^{\mathrm{b}}$ & $3.49^{\mathrm{a}-\mathrm{d}}$ & $3.25^{b c}$ & $2.35^{\mathrm{d}}$ & $4.96^{b}$ & $3.91^{\mathrm{b}-\mathrm{d}}$ \\
\hline ETBW8427 & $5.30^{b-d}$ & $4.70^{\mathrm{bc}}$ & $2.76^{\mathrm{d}-\mathrm{f}}$ & $4.07^{\mathrm{ab}}$ & $3.30^{\mathrm{bc}}$ & $4.84^{\mathrm{b}}$ & $4.16^{\mathrm{a}-\mathrm{c}}$ \\
\hline ETBW8459 & $4.60^{d}$ & $4.45^{b-d}$ & $3.38^{\mathrm{a}-\mathrm{d}}$ & $2.60^{\mathrm{cd}}$ & $3.19 \mathrm{bc}$ & $2.46^{\mathrm{d}}$ & $3.45^{\mathrm{cd}}$ \\
\hline ETBW9037 & $5.99 \mathrm{ab}$ & $5.07^{b}$ & $1.95^{\mathrm{f}}$ & $3.82^{\mathrm{ab}}$ & $2.97^{\mathrm{cd}}$ & $4.85^{b}$ & $4.11^{\mathrm{a}-\mathrm{c}}$ \\
\hline ETBW9045 & $5.04^{b-d}$ & $4.85^{\mathrm{b}}$ & $2.44^{\mathrm{ef}}$ & $4.50^{\mathrm{a}}$ & $3.18^{\mathrm{cd}}$ & $3.39^{c}$ & $3.90^{\mathrm{b}-\mathrm{d}}$ \\
\hline ETBW8075 & $2.23^{\mathrm{e}}$ & $1.24^{\mathrm{f}}$ & $3.21^{\mathrm{a}-\mathrm{e}}$ & $0.38^{\mathrm{f}}$ & $0.91^{\mathrm{e}}$ & $1.23^{\mathrm{e}}$ & $1.53^{\mathrm{e}}$ \\
\hline ETBW9464 & $5.72^{\mathrm{a}-\mathrm{c}}$ & $3.80^{\mathrm{de}}$ & $3.45^{\mathrm{a}-\mathrm{d}}$ & $0.84^{\mathrm{f}}$ & $3.01^{\mathrm{cd}}$ & $3.28^{c}$ & $3.35^{\mathrm{cd}}$ \\
\hline ETBW9466 & $6.43^{\mathrm{a}}$ & $4.08^{\mathrm{c}-\mathrm{e}}$ & $3.87^{\mathrm{a}}$ & $2.74^{\mathrm{cd}}$ & $3.49 \mathrm{bc}$ & $2.86^{\mathrm{cd}}$ & $3.91^{\mathrm{b}-\mathrm{d}}$ \\
\hline ETBW9470 & $6.56^{\mathrm{a}}$ & $6.25^{\mathrm{a}}$ & $3.66^{\mathrm{a}-\mathrm{c}}$ & $4.01^{\mathrm{ab}}$ & $5.69^{a}$ & $3.41^{\mathrm{c}}$ & $4.93^{\mathrm{a}}$ \\
\hline Hidase & $5.94^{\mathrm{ab}}$ & $4.37^{\mathrm{b}-\mathrm{e}}$ & $3.79 \mathrm{ab}$ & $2.62^{\mathrm{cd}}$ & $3.56^{\mathrm{bc}}$ & $5.45^{\mathrm{ab}}$ & $4.29^{\mathrm{a}-\mathrm{c}}$ \\
\hline Mean & $5.15^{\mathrm{a}}$ & $4.33^{\mathrm{b}}$ & $3.17^{\mathrm{de}}$ & $2.86^{\mathrm{e}}$ & $3.32^{\mathrm{d}}$ & $3.82^{c}$ & 3.77 \\
\hline LSD\% & 0.96 & 0.76 & 0.86 & 1.07 & 0.89 & 0.78 & 0.37 \\
\hline
\end{tabular}

N.B. Means with the same letter are not significantly different

Where; LSD= least significant difference and CV= coefficient of variation

Which Won Where Pattern: The polygon view of the GGE biplot was constructed to show which genotypes performed best in which environment (Figure. 1). The polygon view of GGE biplot is the best way for the identification of winning genotypes with visualizing the interaction patterns between genotypes and environments (Yan and Kang, 2003) in MET data analysis, which is helpful in estimating the possible existence of different mega-environments (Yan and Tinker, 2006). The polygon view of a GGE biplot indicates the presence or absence of crossover or noncrossover GE interactions involving the most responsive genotypes and is suggestive of the existence or absence of different mega-environments among the test environments (Yan and Rajcan, 2002). In this biplot, a polygon is formed by connecting the vertex genotypes with straight lines so that the rest of the genotypes are placed within the polygon.

GGE biplot was constructed by plotting the first two principal components, PC1 and PC2, derived from subjecting environment centred yield data to singular value decomposition (Yan et al., 2000). PC1 and PC2 accounted for $82.87 \%$ (63.26 and 19.61\%) of the G + GE variation for grain yield of the genotypes evaluated at six environments. The vertices of the polygon were the genotype markers located farthest away from the biplot origin in various directions, such that all genotype markers were contained within the resulting polygon. Based on this, four genotypes were identified as the markers farthest away from the biplot origin and the 
remaining eleven genotypes lied within this polygon. The vertex genotype in each sector represented the highest yielding genotype in the environment that fell within that particular sector (Yan et al., 2000).

According to Figure. 1, the vertex genotypes were G2 (ETBW8070), G14 (ETBW9470), G12 (ETBW9464) and G11 (ETBW8075). These genotypes were the best or worst in some or all environments because they are farthest from the origin of the biplot (Yan and Kang, 2003) and are more responsive to environmental change and are considered as specifically adapted genotypes. They are best in the environments lying within their respective sector in the polygon view of the GGE-biplot (Yan and Tinker, 2006). G14 (ETBW9470) was the highest yielding genotype at KU (Kulumsa), AS (Asasa) and AR (Arsi Robe). The other vertex genotypes G2 (ETBW8070) was the best performing genotype at BJ (Bekoji) and HL (Holeta). The vertex genotype G11 (ETBW8075) was the poorest genotypes in almost all of the test environments since it had the longest distance from the origin of the biplot on the opposite side of the environments. It ranked $15^{\text {th }}$ in all environments except at Dhera where it ranked $8^{\text {th }}$ by yield estimated from GGE1 and GGE2 (results not presented).

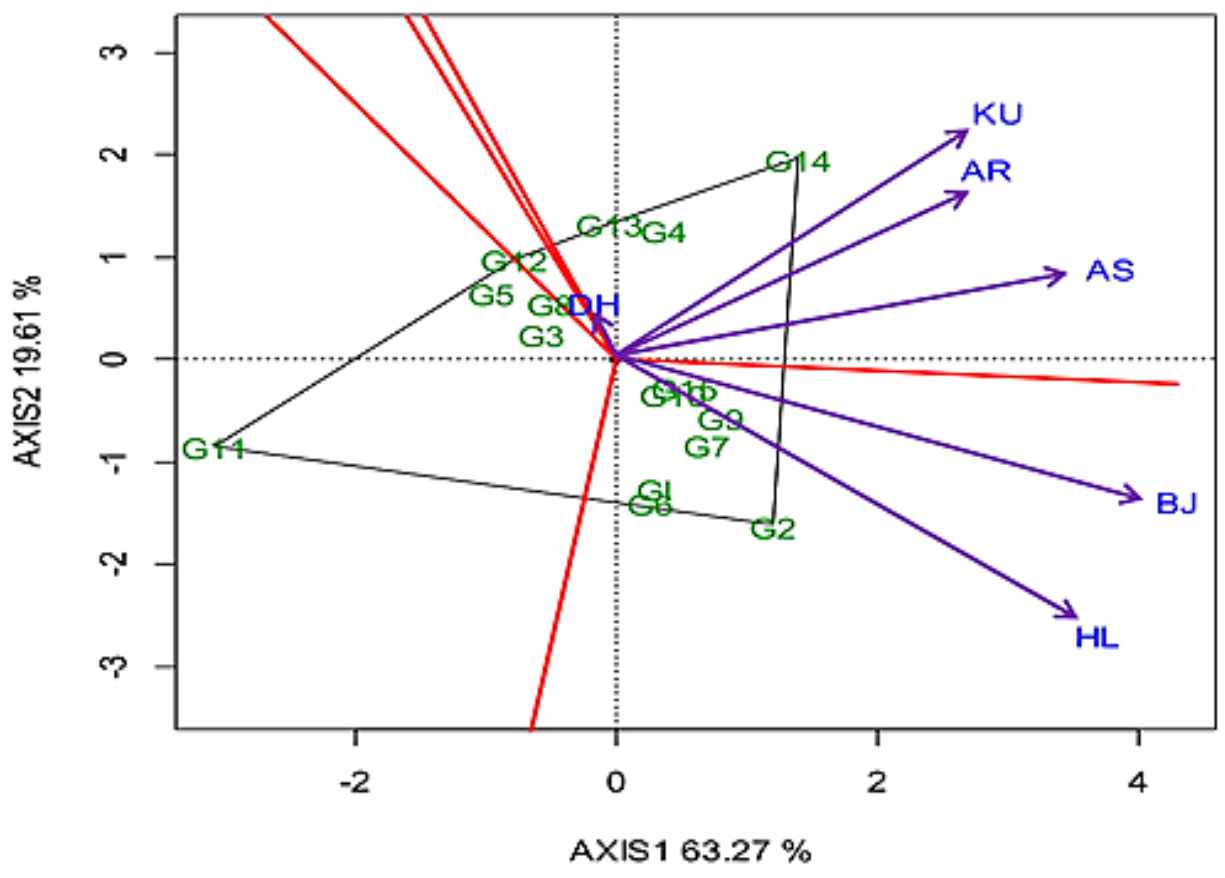

Figure 1. Polygon views of the GGE biplot based on symmetrical scaling for the which-won-where pattern of genotypes and environments.

Where G1=Lemu, G2=ETBW8070, G3=ETBW8078, G4=ETBW8084, G5=ETBW8311, G6=ETBW8065, G7=ETBW8427, G8=ETBW8459, G9=ETBW9037, G10=ETBW9045, G11=ETBW8075, G12=ETBW9464, G13=ETBW9466, G14=ETBW9470, G15=Hidasse, AR=Arsi Robe, AS=Asasa, BJ=Bekoji, DH=Dhera, HL=Holeta and KU=Kulumsa

The environments fall into three quadrants while the genotypes fall into four quadrants (Figure.1). The first quadrant contains three locations KU (Kulumsa), AS (Asasa) and AR (Arsi Robe) and three genotypes G4 (ETBW8084), G13 (ETBW9466) and G14 (ETBW9470) and the vertex genotype for this section was G14(ETBW9470), being the highest yielding genotype at these three locations. Environments within the same sector share the same winning genotype. Asasa and Kulumsa are in the mid-altitude; 2000 and 22000 masl) and obtain a moderate amount of annual rainfall (620 and $890 \mathrm{~mm}$ per annum). They had a shorter growing season (DH of 55 and 75; DM of 109 and 127 and GFP of 54 and 53) than Bekoji and Holeta, with DH of 86 and 63; DM of 167 and 141 and GF of 81 and 78 days (results not presented)). G14 adapted to the quadrant of Kulumsa, Arsi Robe and Asasa was earlier than G2 (ETBW8070) adapted to Bekoji and Holeta. G14(ETBW9470) and G2 (ETBW8070) had DH of 63 and 65, DM of 123 and 128 and GFP of 60 and 63 days, respectively. By average days 
to maturity G2 (128 days) ranked $6^{\text {th }}$ while G14 (123 days) ranked $14^{\text {th }}$ (results not presented). The second quadrant contains one location, Dhera and four genotypes G3 (ETBW8078), G5 (ETBW8311), G8 (ETBW8459) and G12 (ETBW9464) and the vertex genotype for this section was G12 (ETBW9464), although it was not very distinct since G3 (ETBW8070), G4 (ETBW8084) and G6 (ETBW8065) were also very near to the side of that vertex. Dhera had a very short vector and was the least discriminating environment. The GGE biplot is not an excellent model to explain the performance of the 15 wheat genotypes at Dhera. Dhera is a moisture stress area in the rift valley and lies at an altitude of 1650 masl and obtains annual rainfall of $680 \mathrm{~mm}$. Dhera had the shortest growing season (DH, DM and GFP of 50, 94 and 44). The mean DH, DM and GFP of the 15 genotypes were 65, 126 and 62 (results not presented). Such late-maturing genotypes were poorly adapted to Dhera. In recent decades' wheat production is slowly moving into the lowland and moisture stress areas of Ethiopia. The third quadrant contained one genotype G11 (ETBW8075) which was located farthest from the origin and from all of the environments. This genotype was the poorest genotype in all environments, especially at Kulumsa, Asasa, Arsi Robe, Bekoji and Holeta. The last quadrant (IV) contained two environments; BJ (Bekoji) and HL (Holeta) and seven genotypes, G1 (Lemu), G6 (ETBW8065), G7 (ETBW8427), G9 (ETBW9037), G10 (ETBW9045), G15 (Hidasse) and G2 (ETBW8070). Bekoji and Holeta are in the highland agro-ecology at altitudes of 2400 and 2780 masl and obtain a high amount of annual rainfall (1020 and $1044 \mathrm{~mm}$, respectively). The vertex and highest yielding genotype for this section was G2 (ETBW8070). Environments within the same sector share the same winning genotype and environments in different sectors have different winning genotypes.

Mean grain yield and its stability: In GGE biplot methodology, the estimation of yield and stability of genotypes were done by using the average environment coordinate (AEC) methods (Yan, 2001). The best genotype can be defined as the one with the highest yield and stability across environments. In the GGE biplot, genotypes with high PC1 scores have high mean yield and those with low PC2 scores have stable yield across environments (Yan and Tinker, 2006). The line passing through the biplot origin the AEC which is defined by the average of PC1 and PC2 scores for all environments is called the Average Environment
Coordinate (AEC) (Yan and Kang, 2003). The average environment ordinate is represented as a double-headed arrow and points towards lower stability in both directions (Yan and Hunt, 2001).

The genotypes on the left side of the ordinate line had yields less than mean yield. Accordingly, genotypes G11(ETBW8075), G5(ETBW8311), G3(ETBW8078), G12 (ETBW9464), and G8 (ETBW8459) had mean grain yield lower than the grand mean (Figure 2). The genotypes on the right side of the line with double arrows have yield performance greater than mean yield and according to this genotypes G1 (Lemu), G2 (ETBW8070), G4 (ETBW8084), G10 (ETBW9045), G14 (ETBW9470), G13 (ETBW9466), G15 (Hiddase), G7(ETBW8427), G9 (ETBW9037), G6 (ETBW8065) gave mean yields which were higher than grand mean 3.77 ton ha ${ }^{-1}$ (Figure. 3). A longer projection to the AEC ordinate, regardless of the direction, represents a greater tendency of the GE interaction of a genotype, which means it is more variable and less stable across environments or vice versa. For instance, genotype G3 (ETBW8078) and G8 (ETBW8459) were more stable as well as low yielding. Considering simultaneously yield and stability, Genotype G10 (ETBW9045) and G15 (Hiddase) showed the best performances (Figure 2), suggesting their adaptation to a wide range of environments. In studies by Farshadfar et al. (2012) and Mehari et al. (2015) the highest yielding wheat genotypes were stable, a desirable situation for plant breeders. G7(ETBW8427) and G9 (ETBW9037) are most desirable, with a high yield but low stability. G1(Lemu), G4(ETBW8084) and G6 (ETBW8065) may also be considered as desirable. Conversely genotype G2 (ETBW8070) and G14 (ETBW9470) both had a high yield, but were less stable. Genotype G11 (ETBW8075) was the least stable with low yield and had a large contribution to the GEI, having the longest distance from the average environment.

Evaluation of genotypes relative to ideal genotypes: An ideal genotype has the highest mean grain yield and is stable across environments (Yan and Kang, 2003; Farshadfar et al., 2012). Desirable genotypes are those located close to the ideal. Thus, starting from the middle concentric circle pointed with arrow concentric circles were drawn to help visualize the distance between genotypes and the ideal genotype (Yan and Tinker, 2006). The ideal genotype can be used as a benchmark for selection. Genotypes that are far away from the ideal genotype can be rejected in early breeding cycles while 
genotypes that are close to it can be considered in further tests (Yan and Kang, 2003). A genotype is more desirable if it is closer to the 'ideal' genotype (Kaya et al., 2006; Mitrović et al., 2012).

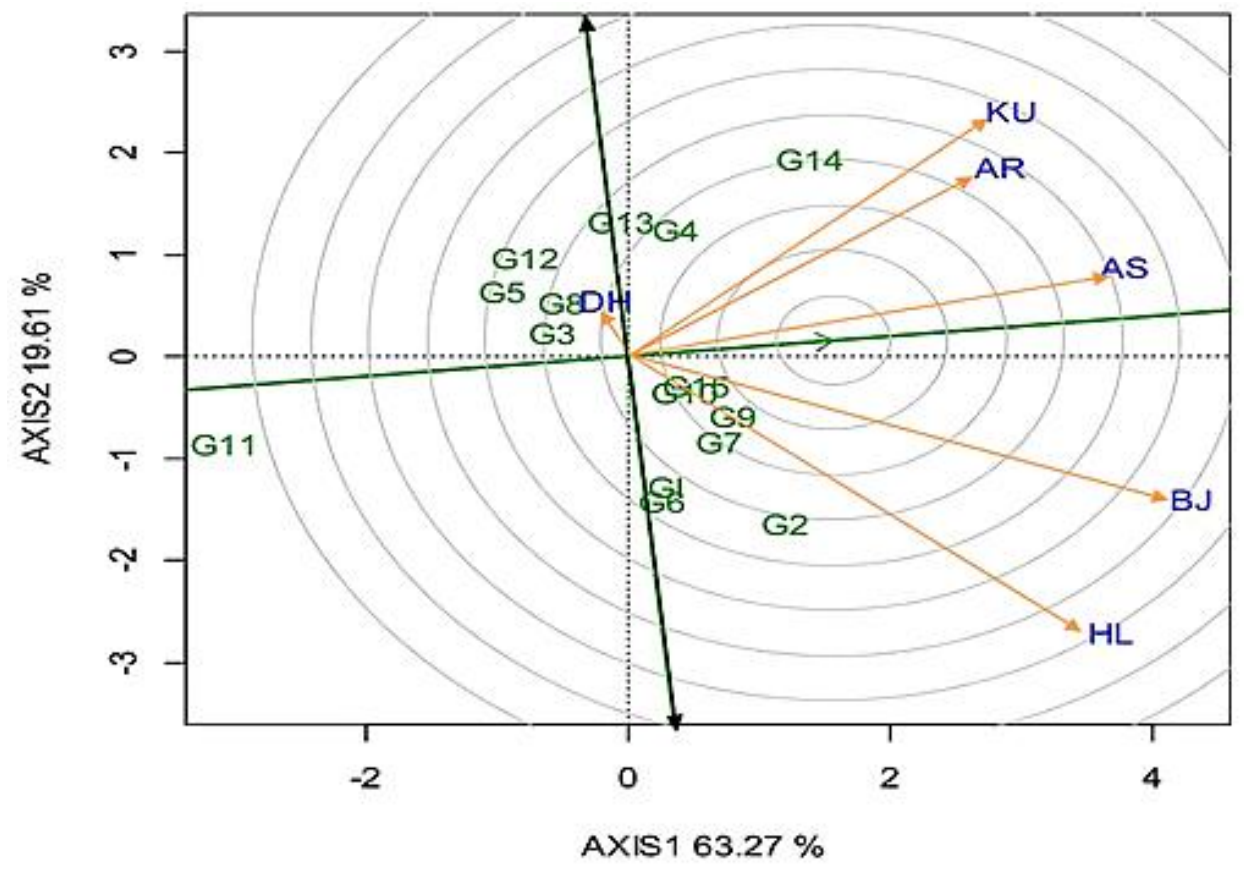

Figure 2. Mean and stability performance of genotypes.

Where G1=Lemu, G2=ETBW8070, G3=ETBW8078, G4=ETBW8084, G5=ETBW8311, G6=ETBW8065, G7=ETBW8427, G8=ETBW8459, G9=ETBW9037, G10=ETBW9045, G11=ETBW8075, G12=ETBW9464, G13=ETBW9466, G14=ETBW9470, G15=Hidasse, AR=Arsi Robe, AS=Asasa, BJ=Bekoji, DH=Dhera, HL=Holeta and KU=Kulumsa

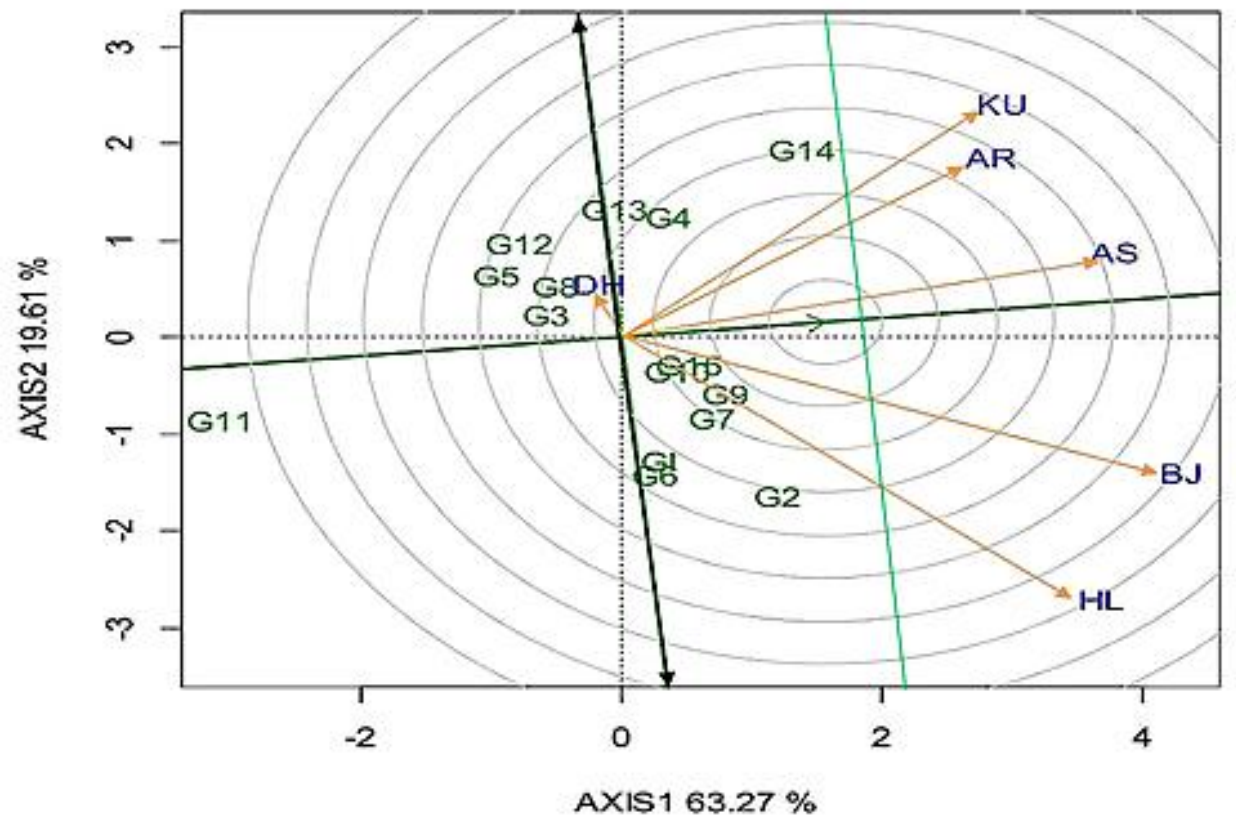

Figure 3. Evaluation of genotypes relative to ideal genotypes.

Where G1=Lemu, G2=ETBW8070, G3=ETBW8078, G4=ETBW8084, G5=ETBW8311, G6= ETBW8065, G7=ETBW8427, G8=ETBW8459, G9=ETBW9037, G10=ETBW9045, G11=ETBW8075, G12=ETBW9464, G13=ETBW9466, G14=ETBW9470, G15=Hidasse, AR=Arsi Robe, AS=Asasa, BJ=Bekoji, DH=Dhera, HL=Holeta and KU=Kulumsa 
The ideal genotype is located in the first concentric circle in the biplot (Figure 3). Therefore, G9 (ETBW9037) was closer to the 'ideal' genotype followed by G15 (Hidase), G10 (ETBW9045) and G7 (ETBW8427) being more desirable than other genotypes (Figure.4). On the other hand, the high yielding genotypes G2 and G14 are undesirable because they are unstable while the lowest yielding genotypes G11 (ETBW8075 and G5 (ETBW8311) were considered to be undesirable because they are placed far from the ideal genotypes. Our results confirm those by Sharma et al. (2010), who found outstanding genotypes near to the ideal genotype in wheat for five consecutive years and those of Akter et al. (2015) who reported an ideal genotype of rice in the first concentric circle.

Evaluation of environments relative to the ideal environments: According to Yan (2001), discriminating ability and representativeness are important properties of a test location. An ideal location should be highly differentiating (discriminating) for the tested genotypes and at the same time be representative of the target locations (Yan and Kang, 2003). The ideal environment is representative and has the highest discriminating power (Yan and Tinker, 2006). Similar to the ideal genotype, the ideal environment is located in the first concentric circle in the environment focused biplot, and desirable environments are close to the ideal environment. Nearest to the first concentric circle, environment Asasa was close to the ideal environment (Figure 4); therefore, it should be regarded as the most suitable to select widely adapted genotypes. On the other hand, DH (Dhera) is at an almost $90^{\circ}$ to the ideal environment and is not correlated to it. It is, therefore, not a representative environment for the other five locations included in this study. The discriminating ability of a location is concerned with the composition of genotypes, but the presence of GEI complicates the identification of an ideal test location (Yan et al., 2000). The test environments should have large PC1 scores in order to discriminate genotypes in terms of the genotypic main effect and should have small PC2 scores in absolute value in order to be more representative of the overall locations (Yan and Rajcan, 2002).

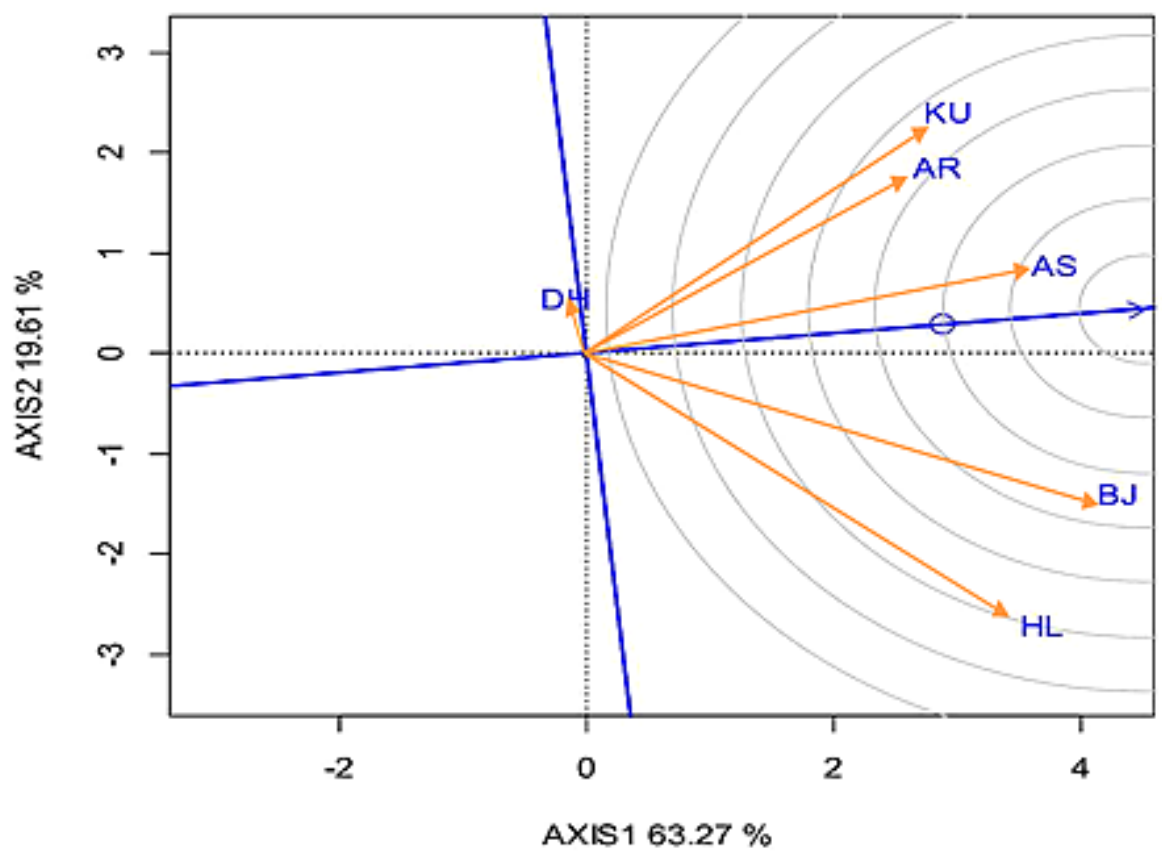

Figure 4. Evaluation of environments relative to ideal environments

Where $\mathrm{AR}=$ Arsi Robe, $\mathrm{AS}=$ Asasa, $\mathrm{BJ}=$ Bekoji, $\mathrm{DH}=$ Dhera, $\mathrm{HL}=$ Holeta and $\mathrm{KU}=$ Kulumsa

The relationship among environments: The GGE biplot in Figure 5 explained $82.68 \%$ of the total variation and can be used for extracting interrelationships among the environments. To visualize the relationship between environments, lines known as environment vectors are drawn to connect the test environments to the biplot 
origin. Further information about the discriminating power of environments, together with a representation of their mutual relationships, can be obtained by the environment-vector view of the GGE-biplot. In this case, along environmental vector reflects a high capacity to discriminate the genotypes. The cosine of the angle between two environments is used to approximate the correlation between them as described and used in Kaya et al. (2006) and Dehghani et al. (2010) and a wide obtuse angle indicates a strong negative correlation, an acute angle indicates a positive correlation while a closeto- $90^{\circ}$ angle indicates lack of correlation (Yan and Tinker, 2006).

According to the angles between test location vectors, the six locations are grouped into three major groups. The smallest angle is between environments $\mathrm{KU}$ (Kulumsa) and AR (Arsi robe), implying that there is a very high correlation between them $\left(\mathrm{r}=0.99^{* *}\right.$ between predicted yield by GGE2). AS (Asasa) is also closer to Arsi Robe, indicating a close correlation between them ( $\mathrm{r}$ $=0.94^{* * *}$ ). The correlation between $\mathrm{KU}$ and AS was ( $\mathrm{r}=$ $0.90^{* * *}$ ). Therefore, the first group KU (Kulumsa), AR (Arsi Robe) and AS (Asasa) were closely correlated (Figure 6) suggesting that these locations provide redundant information on their capacity in discriminating between the genotypes. The second group included HL (Holeta) and BJ (Bekoji) ( $\mathrm{r}=0.95^{* * *}$ ). DH (Dhera) had a very short vector and is alone. The angle between Holata and Dhera was greater than $90^{\circ}$, showing a negative correlation between them $(\mathrm{r}=$ $\left.0.79^{* * *}\right)$. The angle between Asasa and Dhera was around $90^{\circ}$ indicating little or no correlation $(r=-0.05)$ between these environments. The angle between Holata and Kulumsa was less than $90^{\circ}$ indicating that there was some positive correlation between them (0.25). All other locations between them had also a positive correlation between themselves and with Kulumsa and Holeta. Obtaining reliable information on the similarity of environments and their subdivision into groups can enable breeders to use fewer test environments reducing the cost of testing and increasing breeding efficiency. With the longest vectors from the origin, environments HL (Holata) and BJ (Bekoji) were the most discriminating environments. AS (Asasa), AR (Arsi Robe) and KU (Kulumsa) were moderately discriminating while DH (Dhera) was the least discriminating location. At Dhera the range of yield of the 15 genotypes was narrow (1.95 - 3.87 tha $^{-1}$ ) while at Bekoji this range was wide $\left(0.38-4.81\right.$ tha $\left.^{-1}\right)$.

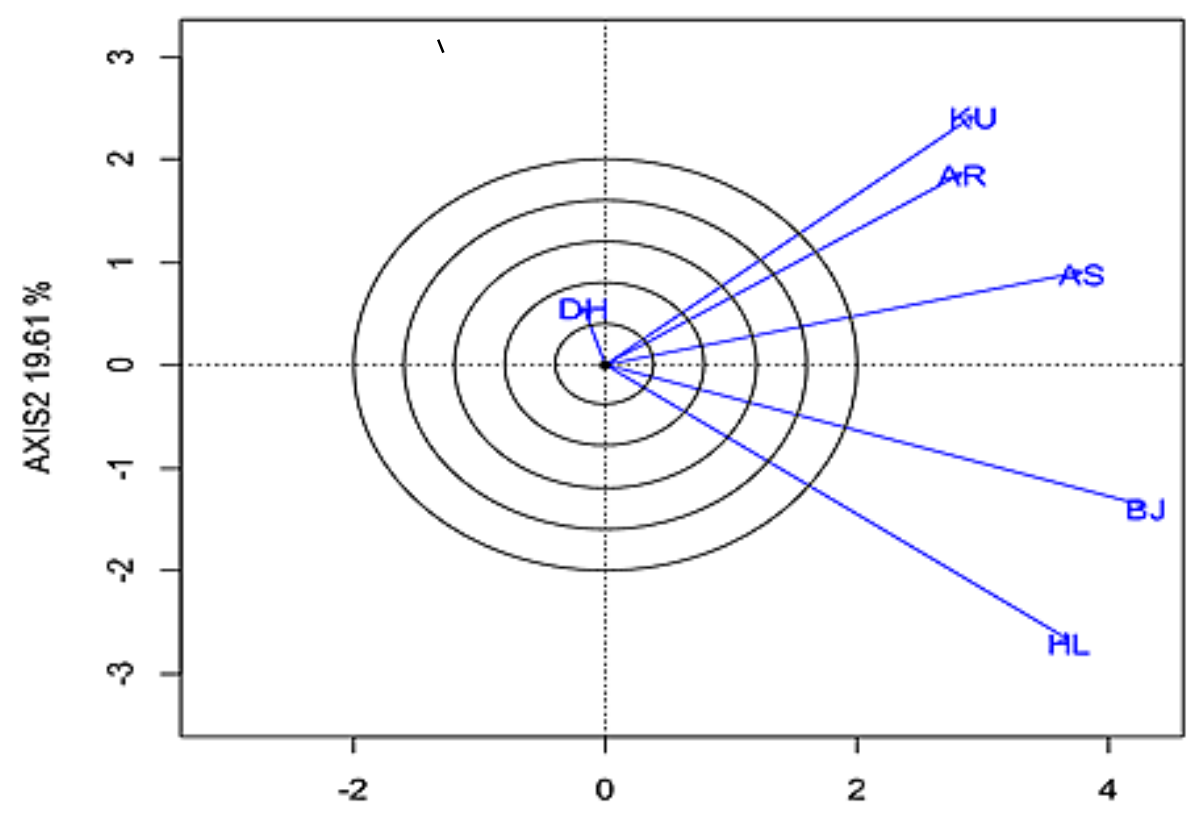

AXIS1 $63.27 \%$

Figure 5. Relationship among environments.

$\mathrm{AR}=$ Arsi Robe, $\mathrm{AS}=$ Asasa, $\mathrm{BJ}=$ Bekoji, $\mathrm{DH}=$ Dhera, $\mathrm{HL}=$ Holeta and $\mathrm{KU}=$ Kulumsa 


\section{CONCLUSION}

A GGE biplot model is an excellent tool for visual MET data analysis. The results of combined analysis of variance for grain yield of 15 bread wheat genotypes indicated that genotype, environment and GEI were highly significant $(\mathrm{P}<0.001)$. The factors explained showed that bread wheat genotypes grain yield was affected by environment (35.28\%), genotype (33.46\%) and GEI (31.45\%). In this GGE biplot, a polygon was formed by connecting the vertex genotypes with straight lines and the rest of the genotypes were placed within the polygon. The vertex genotypes were ETBW8075, ETBW9470, ETBW9464, ETBW8070 and ETBW9037 having the largest distance from the origin. These genotypes are the best or poorest in some or all environments because they are farthest from the origin of biplot which were more responsive to environmental change and are considered as specially adapted genotypes. They are best in the environment lying within their respective sector in the polygon view of the GGE-biplot. Thus, these genotypes are considered specifically adapted. The first two PC axes of GGE explained $88.7 \%$ of G+GEI and divided the six locations into three major groups: Group1 included Asasa, Kulumsa and Arsi Robe (moderately discriminating locations); Group2 had the highland wheat producing locations Holeta and Bekoji (most discriminating locations), while Group3 contain Dhera (least discriminating location), a moisture stress location in the rift valley. Locations within the same group were closely correlated and provided redundant information about the genotypes. Testing can be performed in any one of the locations within a group. Genotype ETBW8078 and ETBW8459 were more stable as well as low yielding. Considering simultaneously yield and stability, genotype ETBW9045 and Hiddase showed the best performances suggesting their adaptation to a wide range of environments. Lemu, ETBW8084 and ETBW8065 were considered as desirable. Genotype ETBW8075 was the least stable with low yield and had a large contribution to the GEI, having the longest distance from the average environment. ETBW9470 was specifically adapted to Group1 locations while ETBW8070 was adapted to Group2 environments. Based on yield performance advanced lines ETBW9470 and ETBW8070 are recommended to be included in variety verification trials for further release.

\section{ACKNOWLEDGEMENTS}

The authors would like to acknowledge the financial support provided by Delivering Genetic Gain in Wheat
(DGGW) Project and Ethiopian Agricultural Research Institute (EARI) for conducting the field trials.

\section{REFERENCE}

Akter, A., M. J. Hasan, U. Kulsum, M. H. Rahman, M. Khatun and M. R. Islam. 2015. GGE Biplot Analysis for Yield Stability in Multi-environment Trials of Promising Hybrid Rice (Oryza sativa L.). Bangladesh Rice Journal, 19: 1-8. https://doi.org/10.3329/bri.v19i1.25213

Central Statistical Agency. 2014. Report on Area and Crop Production forecast for Major Crops (for private Peasant Holdings 'Meher' season). Addis Ababa, Ethiopia.

Dehghani, H., S. H. Sabaghpour and A. Ebadi. 2010. Study of Genotype $\times$ Environment Interaction for Chickpea Yield in Iran. Agronomy Journal, 102: 1. https://doi.org/10.2134/agronj2009.0156

Farshadfar, E., R. Mohammadi, M. Aghaee and Z. Vaisi. 2012. GGE biplot analysis of genotype $x$ environment interaction in wheat-barley disomic addition lines. Australian Journal of Crop Science, 6: 1074-79.

Francis, T. R. and L. W. Kannenberg. 1978. Yield stability studies in short-season maize.: II. Relationship to plant-to-plant variability. Canadian Journal of Plant Science, 58: 1035-39. https://doi.org/10.4141/cjps78-158

Gauch, H. 2006. Winning the Accuracy Game. American Scientist, 94: 133. https://doi.org/10.1511/2006.2.133

Gauch, H. G., H.-P. Piepho and P. Annicchiarico. 2008. Statistical Analysis of Yield Trials by AMMI and GGE: Further Considerations. Crop Science, 48: 866.

https://doi.org/10.2135/cropsci2007.09.0513

Karimizadeh, R., M. Mohammadi, N. Sabaghnia, M. K. Shefazadeh and J. Pouralhossini. 2012. Univariate stability analysis methods for determining genotype $\times$ environment interaction of durum wheat grain yield. African Journal of Biotechnology, 11: 2563-73. https://doi.org/10.5897/AJB11.3093

Kaya, Y., M. Akcura and S. Taner. 2006. GGE-biplot analysis of multi-environment yield trials in bread wheat. Turkish Journal of Field Crops, 30: 325-37.

Mehari, M., M. Tesfay, H. Yirga, A. Mesele, T. Abebe, A. Workineh and B. Amare. 2015. (GGE) biplot 
analysis of genotype-by-environment interaction and grain yield stability of bread wheat genotypes in South Tigray, Ethiopia. Communications in Biometry and Crop Science, 10: 17-26.

Melkamu, T., A. Sentayehu and E. Firdissa. 2015. GGE Biplot Analysis of Genotype by Environment Interaction and Grain Yield Stability of Bread Wheat Genotypes in South East Ethiopia. World Journal of Agricultural Sciences, 11: 183-90.

Mitrović, B., D. Stanisavljević, S. Treskić, M. Stojaković, M. Ivanović, G. Bekavac and M. Rajković. 2012. Evaluation of experimental maize hybrids tested in multi-location trials using AMMI and GGE biplot analyses. Turkish Journal of Field Crops, 17: 35-40.

Mohamed, N. E. and A. A. Ahmed. 2013. Additive main effects and multiplicative interaction and GGE biplot analysis of genotype $\times$ environment interactions for grain yield in bread wheat (Triticum aestivum L.). African Journal of Agricultural Research, 8: 5197-203.

Sharma, R. C., A. I. Morgounov, H. J. Braun, B. Akin, M. Keser, D. Bedoshvili, A. Bagci, C. Martius and M. van Ginkel. 2010. Identifying high yielding stable winter wheat genotypes for irrigated environments in Central and West Asia. Euphytica, 171: 53-64. https://doi.org/10.1007/s10681-009-9992-6

Shiferaw, B., M. Smale, H.-J. Braun, E. Duveiller, M. Reynolds and G. Muricho. 2013. Crops that feed the world 10. Past successes and future challenges to the role played by wheat in global food security. Food Security, 5: 291-317. https://doi.org/10.1007/s12571-013-0263-y

Shukla, G. K. 1972. Some statistical aspects of partitioning genotype-environmental components of variability. Heredity, 29: 237-45. https://doi.org/10.1038/hdy.1972.87

Tarakanovas, P. and V. Ruzgas. 2006. Additive main effect and multiplicative interaction analysis of grain yield of wheat varieties in Lithuania.
Agronomy Research, 4: 91-98.

Temesgen, B., A. Sintayew and T. Zerihun. 2015. Genotype X Environment Interaction and Yield Stabliity of Bread Wheat (Triticum Eastivum L.) Genotype in Ethiopia using the Ammi Analysis. Journal of Biology, Agriculture and Healthcare, 5: 129-39.

Yan, J., Y. Zhang and Z. H. He. 2001. Investigation on paste property of Chinese wheat. Scientia Agricola, 34: 9-13.

Yan, W. 2001. GGEbiplot-A Windows Application for Graphical Analysis of Multienvironment Trial Data and Other Types of Two-Way Data. Agronomy Journal, 93: 1111. https://doi.org/10.2134/agronj2001.9351111x

Yan, W. and L. A. Hunt. 2001. Interpretation of Genotype $\times$ Environment Interaction for Winter Wheat Yield in Ontario. Crop Science, 41: 19. https://doi.org/10.2135/cropsci2001.41119x

Yan, W., L. A. Hunt, Q. Sheng and Z. Szlavnics. 2000. Cultivar Evaluation and Mega-Environment Investigation Based on the GGE Biplot. Crop Science, 40: 597. https://doi.org/10.2135/cropsci2000.403597x

Yan, W. and M. S. Kang. 2003. GGE biplot Analysis: a Graphical Tool for Breeders, Geneticists and Agronomists CRC Press LLC: Boca Roton, Florida.

Yan, W., M. S. Kang, B. Ma, S. Woods and P. L. Cornelius. 2007. GGE Biplot vs. AMMI Analysis of Genotype-by-Environment Data. Crop Science, 47: 643 . https://doi.org/10.2135/cropsci2006.06.0374

Yan, W. and I. Rajcan. 2002. Biplot Analysis of Test Sites and Trait Relations of Soybean in Ontario. Crop Science, 42: 11. https://doi.org/10.2135/cropsci2002.1100

Yan, W. and N. A. Tinker. 2006. Biplot analysis of multienvironment trial data: Principles and applications. Canadian Journal of Plant Science, 86: 623-45. https://doi.org/10.4141/p05-169 